\title{
The effect of combined oestrogen and progesterone replacement on the renal responses to oxytocin and vasopressin in ovariectomized rats
}

\author{
T Eckert, M L Forsling ${ }^{1}$ and H Schwarzberg \\ Institut für Neurophysiologie, Otto-von-Guericke-Universitaet, Leipziger Strasse 44, D-39120 Magdeburg, Germany and ${ }^{1}$ Division of Physiology, \\ King's College, St Thomas' Hospital, Lambeth Palace Road, London SE1 7EH, UK \\ (Correspondence should be addressed to T Eckert)
}

\begin{abstract}
Objective: Renal responsiveness to the neurohypophyseal hormones, oxytocin and vasopressin, has been shown in the rat to vary during pregnancy and lactation. A study was performed to determine whether ovarian steroids could contribute to the observed changes.

Design: Using a previously validated method, fluid excretion during infusion of oxytocin or vasopressin was monitored in ovariectomized animals with and without chronic administration of oestrogen and progesterone.

Methods: After 14 days treatment with vehicle or $12.5 \mathrm{mg}$ hydroxyprogesterone caproate and $0.25 \mathrm{mg}$ oestradiol valerate injected every 3 days, rats were infused with $0.077 \mathrm{~mol} / \mathrm{l} \mathrm{NaCl}$ for an equilibration period of approximately $2.5 \mathrm{~h}$. Timed urine collections for the determination of volume and electrolytes were then made during a control period of at least $45 \mathrm{~min}$ and for $60 \mathrm{~min}$ while the infusate was supplemented with vasopressin $(40 \mathrm{fmol} / \mathrm{min})$ or oxytocin $(50 \mathrm{fmol} / \mathrm{min})$. Further observations were made for a final $90 \mathrm{~min}$ of hypotonic saline infusion. In control infusions saline alone was given.

Results: Treatment with ovarian steroids did not affect the volume of urine excreted during hormone infusion. Electrolyte excretion, however, was affected with lower concentrations of sodium and chloride on oxytocin infusion being seen in the steroid-treated animals. During vasopressin infusion, peak electrolyte concentrations were also achieved later in this group of animals.

Conclusion: The increased circulating concentrations of oestrogen and progesterone seen during pregnancy could contribute to variations in the natriuretic response to neurohypophyseal hormones observed in the rat.
\end{abstract}

European Journal of Endocrinology 141 297-302

\section{Introduction}

Pregnancy and lactation are times of major changes in hormone levels and fluid balance, with smaller changes during the menstrual and oestrous cycles. Two hormones potentially contributing to changes in fluid balance in the rat are oxytocin and arginine vasopressin. Vasopressin, the antidiuretic hormone, plays an important role in osmoregulation and the concentration of urine. Its primary, renal action is a pronounced antidiuresis, but a natriuresis has been observed (1). Oxytocin, which is primarily involved in labour and lactation, has also been shown to elicit renal responses. In rats, administration of physiological doses of oxytocin elicits a diuresis (2) and a natriuresis (3). Studies have shown a dependence of neurohypophyseal hormone release on gonadal steroids (4) and consequently the day of the oestrous cycle (5) and stage of gestation (6). Renal responsiveness to vasopressin and oxytocin also varies over the oestrous cycle $(7,8)$ and during pregnancy and lactation $(9,10)$ in the rat. In order to investigate the role of sustained elevated levels of gonadal steroids, such as seen in pregnancy, in altering renal responsiveness to oxytocin and vasopressin, we performed an investigation in ovariectomized rats given combined oestrogen and progesterone replacement. Initial reports of this work have been published (11).

\section{Materials and methods \\ Animals, housing and maintenance}

Female Sprague-Dawley rats (230-320g) housed under conditions of constant temperature, humidity and lighting (12 h light:12 h darkness, lights on from $0600 \mathrm{~h}$ ) were used throughout the studies. 

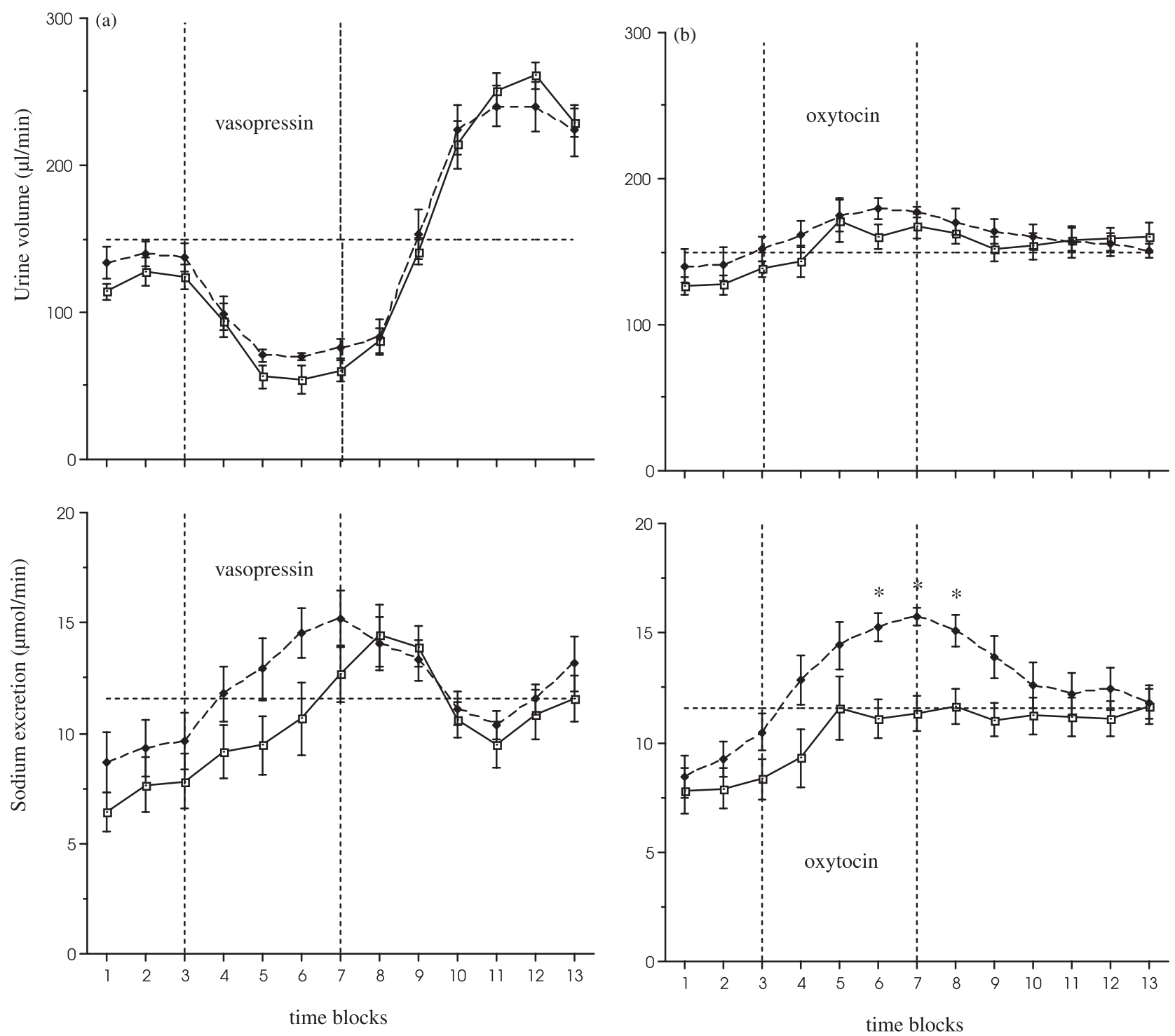

Figure 1 Urine volume and sodium excretion during infusion of hypotonic saline plus vasopressin (a) or oxytocin (b) in steroid-treated ( $\square$ ) and control $(\bullet)$ animals. Values are means \pm S.E.M. The numbers on the abscissa indicate 15 -min periods. The horizontal dashed line indicates rate of infusion. The vertical dashed line indicates time of vasopressin or oxytocin added to the infusion. ${ }^{*} P<0.01$ for steroid vs control.

\section{Preparation of animals}

Two weeks after bilateral ovariectomy under pentobarbital anaesthesia $(50 \mu \mathrm{g} / \mathrm{kg}$ i.p.), the rats were injected with either $0.05 \mathrm{ml}$ Gravibinon $(12.5 \mathrm{mg}$ hydroxyprogesterone caproate and $0.25 \mathrm{mg}$ oestradiol valerate, Schering, Berlin, Germany) or with the vehicle every 3rd day. After at least 12 days the rats were anaesthetized again and each implanted with a jugular cannula.

\section{Protocol}

Following a minimum recovery time of $24 \mathrm{~h}$ the rats were placed in metabolism cages and infused with
$0.077 \mathrm{~mol} / \mathrm{l} \mathrm{NaCl}$ at $150 \mu \mathrm{l} / \mathrm{min}$ for an equilibration period of not less than $2.5 \mathrm{~h}$. Each spontaneous urination was then timed and collected for determination of volume, and sodium, potassium and chloride concentrations. After a control period of at least $45 \mathrm{~min}$ the infusate was supplemented with vasopressin $(40 \mathrm{fmol} / \mathrm{min})$ or oxytocin $(50 \mathrm{fmol} / \mathrm{min})$ for $60 \mathrm{~min}$. Finally saline was resumed for $90 \mathrm{~min}$. Control infusions of saline without added vasopressin or oxytocin were performed to determine the basal urine output and excretion of sodium, chloride and potassium during the infusions in both groups of rats. 


\section{Analysis}

Urinary volume was determined gravimetrically and the concentrations of sodium, potassium and chloride in urine were measured by ion selective electrodes (Radiometer ABL System 625, Radiometer, Copenhagen, Denmark). Plasma hormone levels of oestrogen and progesterone of hormone-replaced $(n=5)$ and vehicletreated $(n=5)$ rats were measured by hard phase chemiluminesence immunoassay (Immulite: DPC Biermann GmbH, Bad Nauheim, Germany). The intra-assay coefficient of variation was $7.1 \%$ for oestrogen and $5.8 \%$ for progesterone.

\section{Statistics}

All values presented are means \pm S.E.M. for group sizes shown. The experimental period was divided into thirteen 15-min time blocks. The first three time blocks represented the first control period showing the basal values during the infusion of hypotonic saline. The next five time blocks showed the response to the hormone and the final time blocks showed the recovery period. Percentage urinary excretion rates on oxytocin and vasopressin supplement were determined by comparing the first control period with the next five time blocks. Variations in peak values, total urinary excretions and plasma hormone concentrations between hormone- and vehicle-treated groups as well as between infusions with and without neurohypophyseal hormone supplement were analysed using unpaired Student's t-test. Variations were considered as significant at the $5 \%$ level.

\section{Results}

\section{Hormone replacement}

Plasma concentrations of oestradiol and progesterone in the hormone-treated group $(n=5)$ were $4.6 \pm 0.2$ and $10.1 \pm 1.4 \mathrm{nmol} / \mathrm{l}$ respectively, and in the control group $(n=5) \quad 0.2 \pm 0.1$ and $3.5 \pm 1.2 \mathrm{nmol} / \mathrm{l}$ (unpaired Student's $t$-test $P<0.05)$.

\section{Control infusions}

There was no significant difference in the basal urine output and electrolyte excretion during the infusion of saline only between the hormone $(n=9)$ and the control $(n=7)$ group. The initial urinary flow rate was $122 \pm 9.5 \mu \mathrm{l} / \mathrm{min}$ in the control group and $130 \pm 8.2 \mu \mathrm{l} / \mathrm{min}$ in the hormone-treated group, while the rates of sodium excretion were $8.5 \pm 0.9$ and $7.6 \pm 0.8 \mu \mathrm{mol} / \mathrm{min}$ respectively. These values did not change significantly during the $3 \mathrm{~h}$ of saline infusion, neither did potassium or chloride excretion change.

\section{Vasopressin}

Vasopressin produced a significant antidiuresis and increased excretion of sodium and chloride in both groups of rats as shown in Fig. 1a and Fig. 2. The vasopressin supplement had no significant effect on the excretion of potassium as compared with the control infusion of saline alone. There was no significant difference between the overall antidiuresis and excretion of sodium and chloride between the hormone-treated $(n=12)$ and vehicle-treated $(n=10)$ groups, although the peak value was achieved later in the hormonetreated group.

\section{Oxytocin}

Oxytocin produced a significant diuresis and increased excretion of sodium and chloride in both groups of rats. It had no influence in the control group $(n=10)$ on the excretion of potassium compared with the control infusion of saline only. The peak values of excretion of sodium and chloride were lower in the hormone-treated group $(n=10)$, as shown in Fig. $1 \mathrm{~b}$ and Fig. 2 $(P<0.01)$. Oxytocin also produced an increase in potassium excretion in this group (Fig. 3).

\section{Discussion}

The experiments confirmed the diuretic and natriuretic effects of oxytocin in the female rat. There were no significant differences in the urinary volume and electrolyte excretion during the infusions of saline alone between the vehicle-treated group and those animals receiving oestrogen and progesterone such that sustained elevated levels of steroid hormones were achieved. The group size employed would be large enough to achieve statistical power in this design of experiment. Although there was no significant difference in the mean diuresis and natriuresis in response to vasopressin in the control and hormone-treated group, the dynamics of the electrolyte response appeared different with the peak excretion being seen earlier in the control group. The differences between the responses of the two groups of animals was more clearly seen following oxytocin infusion when significantly lower peak values in excretion of sodium and chloride were seen after oestrogen and progesterone replacement.

This difference in electrolyte excretion on steroid treatment would mean that during pregnancy fluid balance would be less affected by increased neurohypophyseal hormone secretion, as occurs for example during parturition. The altered electrolyte response is consistent with the observation that at the end of pregnancy the natriuretic response to infusion of neurohypophyseal hormones is lower than during lactation (12). However, steroid treatment had no effect on urine volumes produced on hormone infusion, even though altered responses are seen 

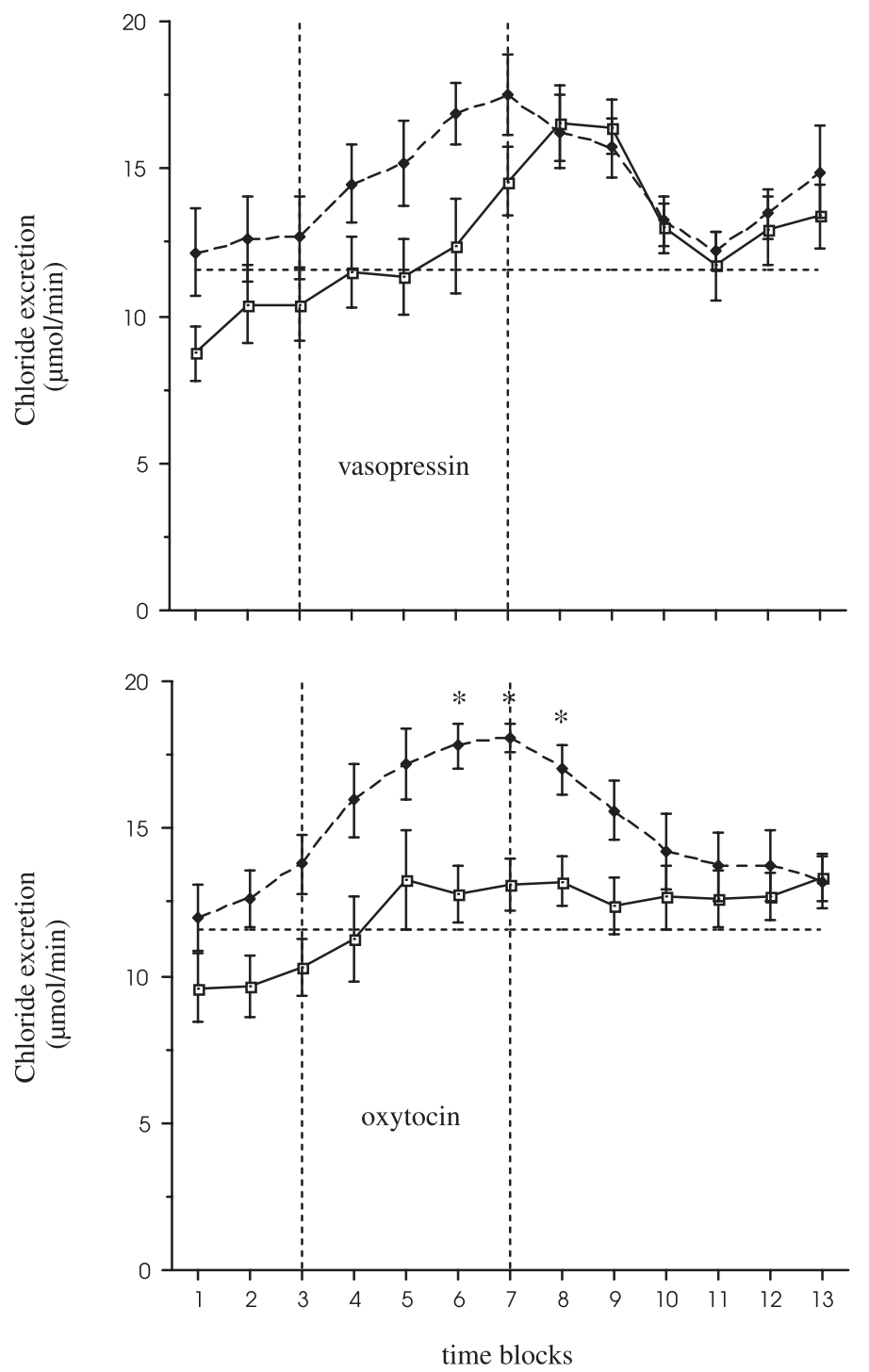

Figure 2 Chloride excretion during infusion of hypotonic saline plus vasopressin or oxytocin in steroid-treated $(\square)$ and control $($ ) animals. Values are means \pm S.E.M. The numbers on the abscissa indicate 15 -min periods. The horizontal dashed line indicates rate of infusion. The vertical dashed line indicates time of vasopressin or oxytocin added to the infusion. ${ }^{*} P<0.01$ for steroid vs control. during pregnancy. This might reflect the fact that during pregnancy there are many different changes including alterations in the pattern of secretion of hormones other than ovarian steroids. In this study the elevated concentrations of ovarian steroids were maintained at a relatively constant level, whereas during pregnancy they would change with time and varying ratios of oestrogen to progesterone would be seen. Dissociation, following steroid treatment, of the changes in volume of urine produced during neurohypophyseal hormone infusion from electrolyte secretion is consistent with the observations during the oestrous cycle when the changes in volume excretion did not parallel those in electrolyte excretion (7). In the present study there was an increase in potassium excretion on oxytocin infusion. Small increases in potassium excretion after administration of vasopressin (13) and oxytocin (2) were also observed in other studies, but the latter were not significant. Vasopressin and oxytocin have been postulated to play a role in kaliuresis (14). We also observed chloride excretion to increase on neurohypophyseal hormone infusion together with sodium excretion confirming reports of other groups (15) which indicate a co-transport.

Oestrogen and progesterone could influence renal responsiveness in a variety of ways. The hormones themselves are renally active with progesterone acting as a competitive agonist at aldosterone receptors in the kidney (16). The alterations in fluid balance could affect the neurohypophyseal system. Water restriction in rats leads to a long-term upregulation in total number of aquaporin-2 water channels in the kidney (17), indicating an influence of changes in fluid balance on renal responsiveness to neurohypophyseal hormones. 
Figure 3 Potassium excretion during infusion of hypotonic saline plus vasopressin or oxytocin in steroid-treated $(\square)$ and control $($ ) animals. Values are means \pm S.E.M. The numbers on the abscissa indicate 15 -min periods. The horizontal dashed line indicates rate of infusion. The vertical dashed line indicates time of vasopressin or oxytocin added to the infusion.

Changes in blood pressure during infusion of neurohypophyseal hormones could contribute to changes in electrolyte excretion. However, doses of oxytocin and vasopressin higher than those used as in our experiments have been shown to elicit changes in blood pressure (18). Gonadal steroids could also affect receptor synthesis or post-receptor mechanisms. Oestrogen has been shown to affect vasopressin binding in a number of tissues (19) and could affect renal receptors. It also increases oxytocin receptor mRNA expression and density in the kidney of the rat (20). Breton et al. (21) confirmed this induction of oxytocin receptor transcripts in the kidney of the rat after oestradiol treatment and, in addition, reported that the oxytocin receptor transcripts found are smaller than those found in the kidney under normal conditions. This would allow for
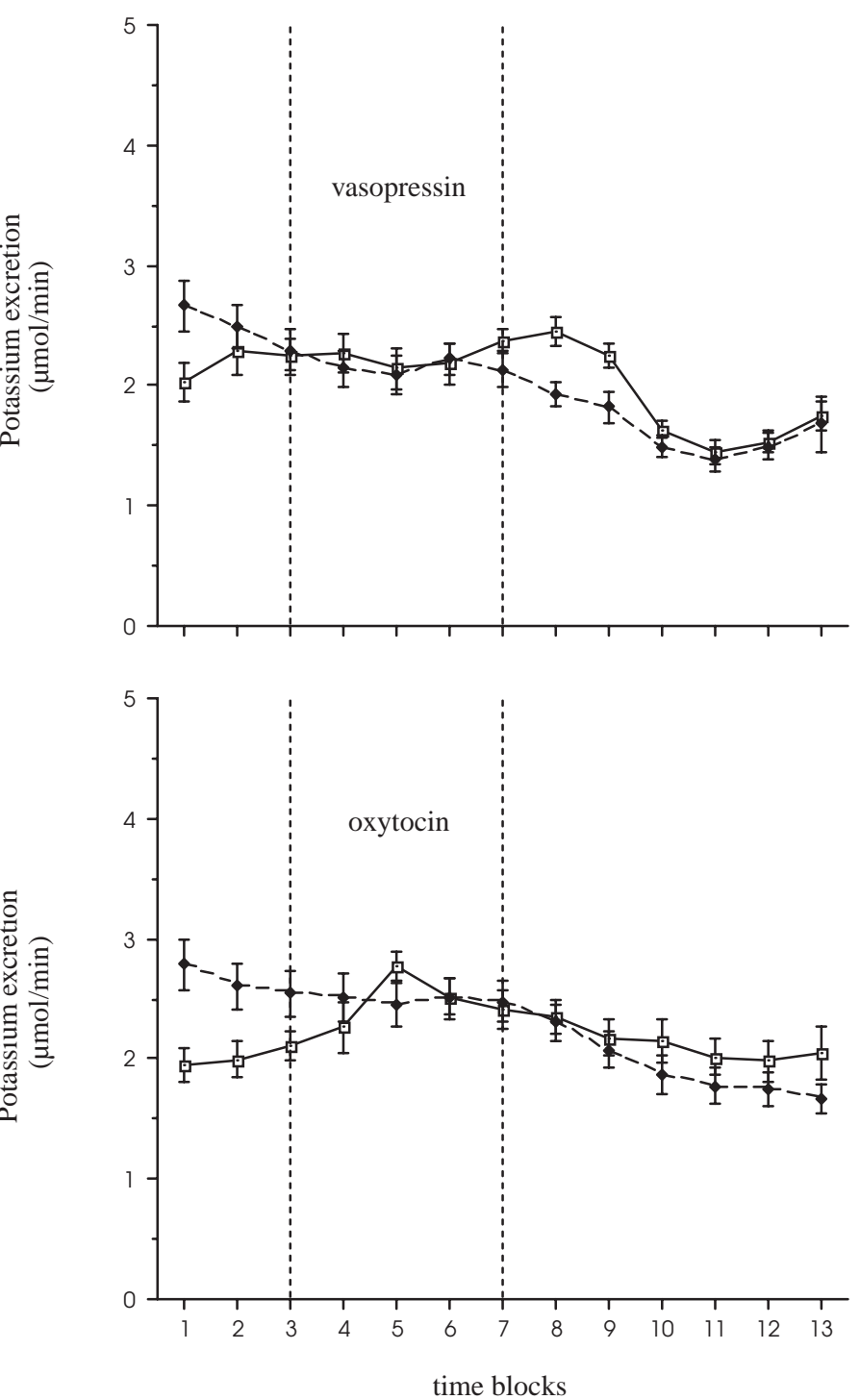

altered stability of the receptors and hence altered responsiveness. While the present study has concentrated on ovarian steroids, other ovarian hormones could be involved in fluid balance and possibly altered renal responsiveness on ovariectomy. For example, administration of relaxin in late pregnant rats induces expression of Fos in the supraoptic and paraventricular nucleus of the hypo-thalamus (22). Relaxin has also been shown to have dipsogenic effects in the rat (23).

In summary, chronic administration of oestrogen in combination with progesterone in ovariectomized rats affects the patterns of electrolyte excretion in response to neurohypophyseal hormones, while leaving water excretion unaffected. These changes could contribute to the altered responses seen during pregnancy. 


\section{Acknowledgements}

Financial support from the Fund for Young Scientists of the Medical Faculty of Otto-von-Guericke-University is gratefully acknowledged.

\section{References}

1 Smith CP \& Balment RJ. Arginine vasopressin-induced natriuresis in the anaesthetised rat: involvement of V1 and V2 receptors. Journal of Endocrinology 1993136 283-288.

2 Windle RJ \& Forsling ML. The renal actions of oxytocin in the conscious rat. Journal of Physiology and Pharmacology 199142 417-426.

3 Verbalis JG, Mangione MP \& Stricker EM. Oxytocin produces natriuresis in rats at physiological plasma concentrations. Endocrinology 1991128 1317-1322.

4 Skowsky WR, Swan L \& Smith P. Effects of sex steroid hormones on arginine vasopressin in intact and castrated male and female rats. Endocrinology 1979104 105-108.

5 Forsling ML \& Peysner K. Pituitary and plasma vasopressin concentrations and fluid balance throughout the oestrous cycle of the rat. Journal of Endocrinology 1988117 397-402.

6 Dürr JA, Stamoutsos B \& Lindheimer MD. Osmoregulation during pregnancy in the rat. Evidence for resetting of the threshold for vasopressin secretion during gestation. Journal of Clinical Investigation $198168337-346$.

7 Forsling ML, Zhou Y \& Windle RJ. The natriuretic actions of vasopressin in the female rat: variations during the 4 days of the oestrous cycle. Journal of Endocrinology 1996148 457-464.

8 Windle RJ \& Forsling ML. Renal responses to oxytocin during the 4 days of oestrous cycle in the rat. Journal of Endocrinology 1997 $154347-354$

9 Herget C, Shah R, Hartley DE, Eckert T \& Forsling ML. The renal responsiveness to oxytocin in the lactating rat. Journal of Physiology 1997504 222P-223P.

10 Shah R, Herget C, Hartley DE, Eckert T \& Forsling ML. The renal responses to vasopressin in the lactating rat. Journal of Physiology 1998507 43P-44P.

11 Eckert T, Forsling ML \& Schwarzberg H. The effect of combined oestrogen and progesterone replacement on the renal actions to oxytocin and vasopressin in ovariectomized rats. Pflügers Archiv 1998435 R212.

12 Hartley DE, Stafford G, Zaman Z \& Forsling ML. Does the renal responsiveness to vasopressin change during pregnancy and lactation in the rat? British Journal of Pharmacology $1996119142 \mathrm{P}$.

13 Brimble MJ, Forsling ML \& Musabayane CT. Natriuretic action of arginine vasopressin in the conscious rat. Acta Endocrinologica $1988119386-390$.

14 Rabinowitz L \& Aizman RI. The central nervous system in potassium homeostasis. Frontiers in Neuroendocrinology 199314 $1-26$.

15 Balment RJ, Brimble MJ \& Forsling ML. Effect of oxytocin on renal sodium and chloride excretion in Long Evans and Brattleboro rats. Journal of Physiology $197929689 \mathrm{P}$.

16 Myles K \& Funder JW. Progesterone binding to mineralocorticoid receptors: in vitro and in vivo studies. American Journal of Physiology 1996270 E601-E607.

17 Knepper MA. Molecular physiology of urinary concentrating mechanism: regulation of aquaporin water channels by vasopressin. American Journal of Physiology 1997272 F3-F12.

18 Forsling ML, Judah JM \& Windle RJ. The effect of vasopressin and oxytocin on glomerular filtration rate in the conscious rat: contribution to the natriuretic response. Journal of Endocrinology $199414159-67$.

19 Laycock JF \& Whitehead SA. Vasopressin and vascular regulation: is sex a factor? Journal of Endocrinology 1995144 389-392.

20 Ostrowski NL, Young WS \& Lolai SJ. Estrogen increases renal oxytocin receptor gene expression. Endocrinology 1995136 1801-1804.

21 Breton C, Neculcea J \& Zingg HH. Renal oxytocin receptor messenger ribonucleic acid: characterization and regulation during pregnancy and in response to ovarian steroid treatment. Endocrinology 1996137 2711-2717.

22 Heine PA, Di S, Ross LR, Anderson LL \& Jacobson CD. Relaxininduced expression of Fos in the forebrain of the late pregnant rat. Neuroendocrinology 199766 38-46.

23 Summerlee AJ, Hornsby DJ \& Ramsey DG. The dipsogenic effects of rat relaxin: the effect of photoperiod and the potential role of relaxin on drinking in pregnancy. Endocrinology 1998139 $2322-2328$.

Received 13 November 1998

Accepted 21 April 1999 